\title{
Improving abortion underreporting in the United States: a cognitive interview study
}

Jennifer Mueller ${ }^{1 *}$, Marielle Kirstein ${ }^{1}$, Alicia VandeVusse ${ }^{1}$, Laura D. Lindberg ${ }^{1}$

${ }^{1}$ Guttmacher Institute, New York, New York, United States

* Corresponding author: Jennifer Mueller, imueller@guttmacher.org

\begin{abstract}
Background: Abortion is a difficult-to-measure behavior with extensive survey underreporting, which compromises the ability to study and monitor abortion. The purpose of this study was to improve our understanding of how women interpret and respond to survey items asking if they have ever had an abortion.

Methods: We developed multiple new questions hypothesized to improve abortion reporting, using approaches that aim to clarify which experiences to report as an induced abortion; reduce the stigma and sensitivity of induced abortion; reduce the sense of intrusiveness of asking about abortion; and increase the motivation to report. We conducted cognitive interviews with cisgender women aged 18-49 in two US states $(\mathrm{N}=64)$ to iteratively assess these new approaches and questions for improving abortion reporting.

Results: Our findings suggest that including abortion as part of a list of other sexual and reproductive health services, asking a yes/no question about lifetime experience of abortion instead of asking about number of abortions, and developing an improved introduction to abortion questions may help to elicit more accurate survey reports.

Conclusions: Opportunities exist to improve survey measurement of abortion. Reducing underreporting of abortion in surveys has the potential to improve sexual and reproductive health research that relies on pregnancy histories.
\end{abstract}

Keywords: abortion, survey reporting, sensitive behaviors, cognitive interview 


\section{Background}

In the United States (US), about one in four women will have an abortion in their lifetime.(1) In 2017, 18\% percent of pregnancies in the US ended in abortion.(2) Despite its frequency, the stigmatization of abortion serves as a significant barrier to the access and provision of abortion services.(3-5) Abortion stigma influences efforts to measure abortion in individual-level surveys in the US and worldwide to different (unknown) degrees.(6) Prior research has documented widespread abortion underreporting by respondents in multiple US surveys.(7) For instance, women reported only $30 \%$ to $40 \%$ of the external counts of abortions in face-to-face (FTF) interviews in the National Survey of Family Growth (NSFG), the National Longitudinal Survey of Youth, and the National Longitudinal Study of Adolescent to Adult Health.(8) Another recent study found that nearly $11 \%$ of pregnancies are missing from the NSFG due to abortion underreporting, and the extent of missing pregnancies differs across demographic groups.(9) Abortion underreporting has broad implications for researchers, service providers, and policy makers, as incomplete pregnancy histories undermine pregnancy and fertility data on which many service provision and budget allocations depend. In the absence of reliable selfreported data, researchers rely on data from health facilities to estimate abortion incidence in the US;(2) this data will be more difficult to obtain if laws restricting the provision of abortions are further expanded.(10)

In response to concerns about abortion data quality, there has been increased attention to innovations that have the potential to improve the accuracy of these data, particularly in settings where abortion is highly restricted. Some research has considered whether respondents fully understand abortion survey questions as intended.(11,12) Some new approaches rely on indirect reports of induced abortions but have not consistently generated reliable estimates of abortion incidence.(13-15) Within the US new approaches have been limited,(16-18) and there remains a need to improve surveys to obtain more complete and accurate abortion reporting from respondents.

Our efforts to understand and improve abortion underreporting draw on a model of the survey response process that involves four key cognitive aspects: comprehension (how respondents interpret the questions), retrieval (how respondents recall information needed to answer a question), judgment (how respondents summarize and shape recalled information), and reporting (how respondents put their response into the required format for the question).(19) To improve the measurement of sensitive behaviors, survey methodologists have generally focused on reporting; Tourangeau and Yan (20) argue that the misreporting of sensitive behaviors is primarily deliberate misreporting due to respondents attempting to answer questions in a socially desirable way. Accordingly, adjustments to survey questions aimed at improving reporting of sensitive items often attempt to reduce social desirability bias. Another potential reason for misreporting is the perceived intrusiveness of the question, which may produce inaccurate data as respondents consider their information "none of your business."(21) One way of decreasing deliberate underreporting may be by increasing 
respondent's motivation to report. The influence of comprehension, retrieval, and judgment on abortion reporting have not received much research attention.

Building from existing literature on the survey response process, particularly for survey reports of sensitive behaviors, we developed a variety of survey questions and approaches that might improve reporting of abortion. We used cognitive interviews to assess these new questions and gain insight into how respondents understand and evaluate abortion questions, as well as how they prefer to report their abortion history. Cognitive interviewing is "an evidence-based, qualitative method specifically designed to investigate whether a survey question...fulfills its intended purpose," (22) by identifying issues that arise in the response process and ultimately improving data quality.(23) Cognitive interviews use the cognitive model of survey response to test participants understanding of survey questions while allowing researchers to probe participants' responses and identify comprehension, retrieval, judgment, and reporting issues. (24) This feedback can be used to guide the design and implementation of new survey items. Through cognitive interviewing, we evaluated newly developed questions and modified versions of existing survey questions to explore potential improvements in self-reports of abortion in surveys.

\section{Methods}

We conducted 64 cognitive interviews with cisgender women in suburban Wisconsin $(\mathrm{N}=35)$ and urban New Jersey $(N=29)$ between January and February 2020. Data collection took place over five days in each state. Study states were selected for their differing abortion climates (abortion rates, clinic numbers, distance to clinics, population opinions on abortion, and legal climate) (25) and to avoid geographically specific findings. In each state, respondents were recruited for an interview described as being about sexual and reproductive health (SRH) by the same third-party recruiting agency. The agency recruited participants from its database of potential respondents who have previously indicated a willingness to being contacted to participate in research on sensitive topics. Eligible participants were aged 18-49, assigned female at birth, identified as women, spoke English, lived in one of the two study states, and had ever had penile-vaginal sex. Participants were asked if they had ever had an abortion during the screening process to ensure respondents included both people who did and did not report a prior abortion. This provided input from a range of respondents, including those who would be able to speak to their personal experiences with abortion. In all but one case, respondents' self-report of abortion at screening matched their self-report during the interview. Each interview lasted approximately 90 minutes, was audio recorded, and was conducted in English. All participants provided verbal consent prior to

i Transgender men, gender-nonconforming, and nonbinary people also become pregnant and need and have abortions. However, they were not included in this study because of the small sample size, which would not allow for comparisons by gender identity or allow for adequate consideration of the role of gender identity in the issues examined in this study. 
the interview during which they were told they could stop the interview at any time or decline to answer any question. The authors' organization's federally registered Institutional Review Board reviewed and approved the study.

For the interview, we developed a set of survey questions about abortion and introductions to questions that we hypothesized could improve abortion reporting through a variety of mechanisms in the survey response process. First, we adapted two question series from the NSFG that ask about abortion in the context of other pregnancies; the NSFG is the primary national survey that attempts to measure abortion and thus these questions serve as the standard protocol or control version for our investigation. In an effort to improve retrieval and reduce social desirability bias, we primed respondents by requesting confidantes' abortion histories before their own. To attempt to reduce social desirability bias, we designed a question which asked respondents to report their abortion as part of a list of other less stigmatized sexual and reproductive health services. We asked a question that explicitly identified different abortion methods to attempt to improve comprehension and separated questions about any abortion experience from the number of abortion experiences to reduce intrusiveness. Finally, we evaluated various new destigmatizing introductions to abortion questions as compared to the current NSFG introduction to increase response motivation and reduce social desirability bias.

Two members of the research team (authors AV and JM) conducted the interviews in private rooms at conference venues and market research locations. Questions and response options were presented to respondents on laminated cards and read aloud by the interviewer. Respondents answered the questions verbally and/or by marking their response on the card. Interview questions were presented in a random order. After respondents were asked a question, interviewers probed for extensive feedback about how they formed their response, defined selected terms, and felt about the question. Once a respondent had been exposed to all of the questions, they were asked to select their most and least preferred questions as well as whether and why they felt a specific question would encourage or discourage accurate reporting of an abortion. After seeing all questions and introductions, respondents were asked to reflect on their overall preferences for answering abortion questions on a survey. Immediately following the interview, participants completed a short sociodemographic questionnaire and received $\$ 150$ cash as a token of appreciation for their time. At the end of each day of interviews, the interviewers debriefed on the day's findings and revised the interview guide and questions to improve question clarity and address respondent feedback regarding question wording. After completing interviews in Wisconsin, questions and probes were added, edited, and removed to improve comprehension and incorporate respondent feedback and preferences before conducting the interviews in New Jersey.

Audio recordings of the interviews were sent to a professional transcription service before being checked for accuracy and stripped of identifying information by research staff. Deidentified transcripts were 
uploaded to NVivo12 for a systematic content analysis to organize responses by theme and assign codes to meaningful segments of the transcript. Three members of the research team (AV, JM, MK) developed a deductive coding scheme based on the interview guide and existing literature. The research team independently coded several interview transcripts and then met to resolve differences and refine the coding scheme as needed. The remaining interviews were divided and coded by at least one member of the research team. The team met regularly to resolve questions and ensure alignment between each coder's application of the coding scheme. Once coding was complete, the team identified salient themes and used matrices to organize the findings. We explored differences in major themes by respondent abortion report.

\section{Results}

Table 1 reports the samples' demographic characteristics. We conducted slightly fewer interviews in New Jersey $(n=29)$ compared to Wisconsin $(n=35)$, and approximately half of the interviews were conducted with respondents who reported prior abortions during screening $(n=33)$. Three-quarters of the sample was between the ages of 28 and 49. Almost half of the respondents were non-Hispanic White, one-quarter were Hispanic, less than one-fifth were non-Hispanic Black, and less than one-fifth reported other or multiple races. Participants were highly educated, and most were at least 200\% over the federal poverty level (FPL). All respondents identified as heterosexual or straight (not shown).

Table 1. Respondents by demographic characteristic $(\mathrm{N}=64)$

\begin{tabular}{|l|l|c|c|}
\hline \multicolumn{2}{|l|}{ Characteristic } & $\mathbf{n}$ & $\mathbf{\%}$ \\
\hline \multirow{3}{*}{ State } & New Jersey & 29 & 45 \\
\cline { 2 - 4 } & Wisconsin & 35 & 55 \\
\hline \multirow{4}{*}{ Abortion } & Yes & 33 & 52 \\
\cline { 2 - 4 } & No & 31 & 48 \\
\hline \multirow{4}{*}{ Poverty status } & $18-27$ & 14 & 22 \\
\cline { 2 - 4 } & $28-38$ & 23 & 36 \\
\cline { 2 - 4 } & $39-49$ & 27 & 42 \\
\cline { 2 - 4 } & $<100 \%$ FPL & 1 & 2 \\
\cline { 2 - 4 } & $100-199 \%$ FPL & 11 & 17 \\
\cline { 2 - 4 } & $200-299 \%$ FPL & 29 & 45 \\
\cline { 2 - 4 } & $300+\%$ FPL & 23 & 36 \\
\hline \multirow{5}{*}{ Race/ethnicity } & Non-Hispanic White & 26 & 41 \\
\cline { 2 - 4 } & Non-Hispanic Black & 11 & 17 \\
\cline { 2 - 4 } & Hispanic & 16 & 25 \\
\cline { 2 - 4 } & Other/multiple races & 28 & 16 \\
\hline \multirow{3}{*}{ Marital status } & Living with partner & & 44 \\
\cline { 2 - 4 } & Married & 10 & \\
\hline
\end{tabular}




\begin{tabular}{|l|l|c|c|}
\hline & Other & 28 & 44 \\
\hline \multirow{4}{*}{ Education } & High school graduate or GED & 3 & 5 \\
\cline { 2 - 4 } & $\begin{array}{l}\text { Some college or associate } \\
\text { degree }\end{array}$ & 34 & 53 \\
\cline { 2 - 4 } & College graduate or above & 27 & 42 \\
\hline \multirow{2}{*}{ Previous births } & None & 21 & 33 \\
\cline { 2 - 4 } & One or more & 43 & 67 \\
\hline
\end{tabular}

When presenting quotes from participants, we identify respondents based on their abortion report, consistent with how we structured our analyses. We only mention differences between respondents who did and did not report prior abortions if abortion history appeared to notably influence responses. We did not find major differences by state. Results are organized around the survey question approaches we tested (e.g., asking about abortion with other pregnancy outcomes, priming by asking about confidantes' abortions) and how stigma influences reporting, as described by our respondents. (Tables 2 and 3 show initial language used, while Appendix Table 1 shows modified wordings).

Table 2. Initial question wordings used in the cognitive interviews

\begin{tabular}{|c|c|c|}
\hline \multicolumn{2}{|r|}{ Approach } & Question Wording \\
\hline 1 & $\begin{array}{l}\text { Pregnancy context } \\
\text { (modified NSFG } \\
\text { ACASI) }\end{array}$ & $\begin{array}{l}\text { Sometimes women are reluctant to tell an interviewer about some of } \\
\text { their pregnancies, especially those pregnancies that ended in abortion } \\
\text { or with babies they no longer live with. In the next set of questions, } \\
\text { please give a complete count of all your pregnancies. } \\
\text { In your lifetime, how many pregnancies have you had that resulted in a } \\
\text { live birth, that is, in a baby born alive? [\#] } \\
\text { In your lifetime, how many pregnancies have you had that ended in } \\
\text { miscarriage, stillbirth, or ectopic pregnancy? [\#] } \\
\text { In your lifetime, how many pregnancies have you had that ended in } \\
\text { abortion? [\#] }\end{array}$ \\
\hline 2 & $\begin{array}{l}\text { Pregnancy context } \\
\text { (modified NSFG } \\
\text { FTF) }\end{array}$ & How many times have you been pregnant in your life? [\#] \\
\hline 3 & $\begin{array}{l}\text { Priming using } \\
\text { confidantes }\end{array}$ & $\begin{array}{l}\text { As far as you know, have any of your friends or family ever had an } \\
\text { abortion? [Yes/No] }\end{array}$ \\
\hline
\end{tabular}




\begin{tabular}{|c|c|c|}
\hline 4 & $\begin{array}{l}\text { Sexual and } \\
\text { reproductive health } \\
\text { services context } \\
\text { (modified NSFG } \\
\text { FTF) }\end{array}$ & $\begin{array}{l}\text { Have you ever received any of the following birth control services } \\
\text { shown on this card from a doctor or other medical care provider? } \\
\text { [Yes/No] } \\
\text { - A method of birth control or a prescription for a method? [Yes/No] } \\
\text { - A check-up or medical test related to using a birth control method? } \\
\text { [Yes/No] } \\
\text { - Counseling or information about birth control? [Yes/No] } \\
\text { - A sterilizing operation? [Yes/No] } \\
\text { - Counseling or information about getting sterilized? [Yes/No] } \\
\text { - Emergency contraception, also known as "Plan B" or the "Morning- } \\
\text { after pill," or a prescription for it? [Yes/No] } \\
\text { - Counseling or information about Emergency contraception, also } \\
\text { known as "Plan B" or the "Morning-after pill"? [Yes/No] } \\
\text { We're also interested in where women go to get other kinds of } \\
\text { reproductive health care. Please look at this new sheet. In your lifetime, } \\
\text { have you received any of the following medical services from a doctor } \\
\text { or other medical care provider? } \\
\text { - A pregnancy test? [Yes/No] } \\
\text { - An abortion? [Yes/No] } \\
\text { - A Pap test - where a doctor or nurse puts an instrument in the vagina } \\
\text { and takes a sample to check for abnormal cells that could turn into } \\
\text { cervical cancer? [Yes/No] } \\
\text { - A pelvic exam - where a doctor or nurse puts one hand in the vagina } \\
\text { and the other on the abdomen? [Yes/No] } \\
\text { - Prenatal care? [Yes/No] } \\
\text { - Post-pregnancy care? [Yes/No] } \\
\text { - A test for a sexually transmitted disease? [Yes/No] }\end{array}$ \\
\hline 5 & $\begin{array}{l}\text { Specifying abortion } \\
\text { methods }\end{array}$ & $\begin{array}{l}\text { People think about abortion differently. When we say abortion, we're } \\
\text { including people who have a surgical procedure, and people who take } \\
\text { medications that end a pregnancy. Using that definition, have you ever } \\
\text { had an abortion? [Yes/No] }\end{array}$ \\
\hline 6 & $\begin{array}{l}\text { Separating any and } \\
\text { number of abortions }\end{array}$ & $\begin{array}{l}\text { Have you ever had an abortion? [Yes/No] } \\
\text { How many abortions have you had in your lifetime? [\#] }\end{array}$ \\
\hline
\end{tabular}

Note: Response options given in brackets

\section{Pregnancy context}

We tested the NSFG approach of asking about abortion within the context of other pregnancies (Table 2, Approaches 1 and 2). During the cognitive interviews, we learned that respondents that had reported an abortion consistently expressed their desire to keep their abortion history separate from their other pregnancies.

I feel like for my situation, if someone asked me, you've been pregnant three times but they see you only have two kids, they say, where is the third one? So, then you kind of have to explain. (Reported an abortion) 
A few respondents did not include their abortions when providing their total number of pregnancies, associating "pregnancy" only with live births or wanted pregnancies, suggesting that comprehension could be an issue for this approach.

The word "pregnant" seems to suggest that it's wanted and voluntary, maybe. So, if the goal is to get information on abortion, focusing on words like pregnant might put off some people. (Reported an abortion)

However, others felt that separate questions for different pregnancy outcomes could be helpful for correctly cataloguing pregnancy experiences.

I'm okay with it. It doesn't bother me. I think it's very specific. I liked that they kind of put it, you know, miscarriage/stillbirth/ ectopic. I think it's important that you specify because I think that can be a very like big question otherwise. (Did not report an abortion)

When asked about pregnancies that "ended in abortion," some respondents suggested that this wording removed "fault," which could facilitate reporting.

You could have said, "bow many pregnancies have you had that you aborted" or that you have had an abortion, something with you, but you are not asking me personally, if it was my choice, I did it, but it ended in abortion. For some reason or the other. So, it could be maybe my life was in danger and the doctor decided. Of course, I would have had to go along with him, but it doesn't put the [pause] all the pressure on me. (Reported an abortion)

In contrast, other respondents felt that this wording was "loaded" and judgmental, potentially "triggering" to someone who had an abortion because it emphasizes that the pregnancy had ended. Respondents who did not report an abortion also described how the question reminded them of something that would be asked by a healthcare provider, and that they felt it would be easy for anyone to answer.

\section{Priming using confidantes}

To prime women to be more willing to report sensitive abortion information, the next approach asked women to report either whether or how many women they know who had an abortion before being asked about their own abortion experiences (Table 2, Approach 3). After respondents had been exposed to the rest of the questions, we probed about how reporting confidante experiences affected their experience answering questions about their own abortion history. Some reported that the experience of thinking of their friends and family made them feel less alone.

It's nice to know that there [are] people and that you're not alone. It makes it a little bit easier. (Reported an abortion) 
However, few respondents reported that thinking of others affected their willingness to report.

I mean it doesn't really affect how I answer any other questions having to think about it because I mean my answer is my answer. So I had it done. So it's not going to change like how I answer or what I answer so it didn't really affect my thought processes how to answer the questions at all. (Reported an abortion)

Not all respondents knew someone else who had had an abortion, and among them, some felt that knowing someone might make it easier to talk about.

I think if I had known anyone else going through the same experience or had in the past, it would make it easier to be more transparent, just because you know you're not alone in it. I think. if you feel like you are an island and nobody else around you bas done it, it's a little bit harder. (Reported an abortion)

\section{Sexual and reproductive health services context}

To reduce social desirability bias, we attempted to contextualize abortion care within a series of other SRH services one could receive from a medical care provider (Table 2, Approach 4). This approach was the most preferred of all presented questions for both respondents who reported abortions and those who did not. Participants reported that they liked being asked about abortion alongside other SRH services, as abortion was normalized when cushioned with other topics. The format also reminded them of answering questions at a health care provider's office, which they felt was an appropriate environment for these questions.

Interviewer: Out of all of these options, which one do you like the best?

Respondent: [...] Definitely the list because it's more comfortable. Because, at some point, the majority, we have had a pregnancy test. So, even at the pharmacy. And, the question on abortion, it's like it's hidden. So, maybe it's bidden for some people not to be asked directly. So, it's bidden in a couple of different questions. (Reported an abortion)

Respondents also liked that this approach allowed them to report their abortion history in a checklist format, as it was quick, straightforward, and limited the amount of time respondents "dwell" on abortion.

[I like the list] Just because it's filled in with a lot of other things that a lot of women do all the time. It's a little easier to answer this because it's on a list. That makes it not as taboo. So, you're just answering normal questions that normal people always go through. (Reported an abortion) 


\section{Specifying abortion methods}

We attempted to improve comprehension by explicitly naming medication and surgical abortion methods when asking respondents for their abortion history (Table 2, Approach 5). However, we found that many respondents did not know what medication abortion was or were unfamiliar with the method used in their abortion(s), indicating that this approach created comprehension issues.

I can see where it can confuse people because it's like, well I just had an abortion; I don't know if it was surgical or medication. [...] I think it can confuse people, like I said, if they don't understand there's two different types of abortions. They may say, "Well, I had an abortion, I don't know what I had. I just had it done." (Reported an abortion)

Explicitly mentioning medication abortion highlighted many respondents' uncertainty about the difference between medication abortion and using emergency contraceptive (EC) pills.

I think it's a good question because as it states, people think differently about abortion. And in the back of my mind, like I didn't really consider like the morning after pill a form of abortion. So this question explains that and says, "Okay, now that you have that information; have you had it, ever had an abortion?" (Reported an abortion)

Overall, feedback on this question was largely negative, as some participants felt the question centered too much on the details of abortion procedures. For some, this focus was described as unnecessary, felt intrusive, "clinical," or "technical," and evoked unwanted memories of their abortion experiences.

I think if you have had an abortion, whether it was surgical or medical, you know that you bave. So, I don't think that it's necessary to point out the different methods. (Reported an abortion)

It makes you think about the actual... because surgical, you know how it's done, but you also know how medication works. So, you think about it, and you get like, surgical, it's a horrible way. (Reported an abortion)

\section{Separating any and number of abortions}

To explore how intrusiveness influences willingness to report abortions, we asked respondents whether they had had an abortion separately from asking about the number of abortions (Table 2, Approach 6). When asked to compare the experience of answering a yes/no question on abortion to the experience of disclosing the number of abortions, almost all respondents preferred answering a yes/no question.

Respondents generally reported that the yes/no question was straightforward, but they had conflicting feedback as to whether this question felt intrusive. Some respondents expressed that this was "not anyone's 
business" or that it was "too personal," in contrast, others felt that the direct nature of the question kept it general and involved less "digging" into their personal lives as compared to other abortion questions.

It's not digging too deep even into your medical history because it doesn't ask the specifics about well, you have had an abortion. Well, how many times? And, you know... This is just - it's information that's provided or given and then you bad just have an option to answer very generally, yes or no. (Reported an abortion)

Respondents overwhelmingly felt that the open-ended question asking about the number of abortions they had was too intrusive and required disclosing too much information. Many respondents referenced concerns about the social desirability of their answers, particularly among those reporting more than one abortion.

[Any] would definitely be easier [to answer], because if I have to put a number here, that's like, "oh my god, I had like 10 abortions. What wrong with me?" [...] Yes, I had and that's it. I can have one or 20 and nobody is going to know nothing about me, but here... like I said, even if you put down two, it is more personal. That's getting a little personal there. (Reported an abortion)

I think maybe some people would feel differently. I think if they have more than one, they'd be uncomfortable. Personally, if I had more than one, I would feel shameful or guilty about that, just because I didn't learn from the... mistake, I guess. (Reported an abortion)

In contrast, a few respondents felt asking about the number of abortions could be comforting and less judgmental than other approaches since the question could be read as assuming the respondent had an abortion.

Respondents suggested that they would prefer only to be asked to report the number of abortions if this information is needed for a specific purpose. However, respondents preferred to only be asked one question, if possible, rather than first asked the yes/no question and then asked for the number.

In an alternate approach, respondents were asked a series of questions requesting information about the number of pregnancies they had, followed by questions about how each pregnancy ended. Here, some respondents who had abortions felt uncomfortable about the request for a number of pregnancies.

I think that, again, the difficulty is just what, you know, what you live with after the fact, what you feel after the fact.

Like I made this decision four times, um, which also, if I can be honest is very irresponsible. (Reported an abortion)

Notably, most respondents answering these series of questions reported that retrieval was not an issue and named that it was not challenging to remember how many abortions they had ever had. 
It shouldn't be difficult. If anybody got pregnant, they should know this. Either they had the child or didn't have the child. (Did not report an abortion)

\section{Destigmatizing and motivating introductions}

We also developed and modified introductions to abortion questions to increase response motivation and reduce the impact of social desirability bias. We asked respondents whether they would want to see an introduction before a question about their abortion history; the majority felt that an introduction should be used to ease respondents into the question, explain why they were being asked the question, and to convey that the respondent is not alone. Those who reported not wanting an introduction felt it could have a negative effect as it drew additional attention to being asked about abortion.

Table 3. Initial introduction wordings used in the cognitive interviews

\begin{tabular}{|c|c|c|}
\hline \multicolumn{2}{|r|}{ Option } & \multirow{2}{*}{$\begin{array}{l}\text { Introduction Wordings } \\
\text { Sometimes women are reluctant to tell an interviewer about } \\
\text { some of their pregnancies, especially those pregnancies that } \\
\text { ended in abortion or with babies they no longer live with. }\end{array}$} \\
\hline 1 & $\begin{array}{l}\text { Reluctance } \\
\text { (modified } \\
\text { NSFG ACASI) }\end{array}$ & \\
\hline 2 & Helping & $\begin{array}{l}\text { The following question is one of the most important in this } \\
\text { interview because it will help to improve family planning and } \\
\text { health services for all women. }\end{array}$ \\
\hline 3 & Common & $\begin{array}{l}\text { Abortion is a common experience and there are a lot of reasons } \\
\text { why people get abortions. }\end{array}$ \\
\hline \multirow[t]{2}{*}{4} & Statistic & 1 in 4 American women will have an abortion in their lifetime. \\
\hline & & $\begin{array}{l}\text { Research shows that } 1 \text { in } 4 \text { American women will have an } \\
\text { abortion in their lifetime. }\end{array}$ \\
\hline 5 & Legal & Abortion is a legal medical procedure in the United States. \\
\hline
\end{tabular}

The current NSFG introduction, which we term the 'Reluctance' introduction (Table 3, Option 1), was frequently reported as the least favorite introduction among the options shared with participants. Regardless of personal abortion history, respondents did not like the phrase "babies they no longer live with," commenting that it was insensitive to the complexities of choosing whether to parent.

But at the time, the only right thing to do was give them up for adoption. So, it's just the way it says "or with babies they no longer live with". That just seems to me that that's kind of an insensitive way of putting that. (Reported an abortion) 
Respondents labeled the language and terminology "negative." Although some felt it was an accurate representation of how they felt responding to the question, they voiced concern that mentioning feeling "reluctant" would actually encourage misreporting.

This would make me more probably not want to say, because I feel like it's like, they know I'm not going to tell anyway. So, I might as well not tell. They don't trust me anyway, so I'm not going to be honest. (Reported an abortion)

Of the different introductions we explored, respondents most preferred the 'Helping' introduction (Table 3, Option 2). Many respondents who reported an abortion felt this introduction was motivational, explained why personal information was being requested, and removed focus from the respondents' abortion experience.

This one seems like they're asking for purposes of not just personal information, but for information to belp all women and to do something about women's health services and family planning... (Reported an abortion)

However, some respondents were skeptical that their report would help other women and subsequently felt the introduction was misleading. Others felt that this introduction gave too much importance to the question.

See, I would have to question this. [...] how does it improve family planning if I say yes, I had an abortion, or no, I had [n't had] an abortion? (Reported an abortion)

In response to the 'Common' introduction (Table 3, Option 3), most respondents who did not report an abortion (and some who did) disagreed with the statement that abortion is common or felt that the commonality should not be highlighted.

It's a common experience, but nobody is going to see it as a common experience. You're not breaking your leg. (Reported an abortion)

However, many respondents selected the 'Common' introduction as their favorite citing that the language was appealing because it highlighted that they were "not the only one" that has had an abortion.

I think it would probably be encouraging to respond in a truthful manner because it's kind of allowing, it's taking away any kind of judgment. It's saying that there's, you know, it's a shared experience or it's something that happens to a lot of people or a lot of women and that there are reasons I think. that a lot of women judge themselves on their choices or feel others judge them without understanding that there are so many different reasons why pregnancies are terminated. (Reported an abortion)

Feedback on the 'Statistic' introduction centered in part on whether "one in four" was an accurate statistic, with some assuming it was overstating the prevalence of abortion while others viewed it as an undercount 
(Table 3, Option 4). Respondents also focused on whether "one in four" made abortion seem common or uncommon, with differing views on these concerns.

Some respondents who reported an abortion felt "singled out" by the mental imagery of being the one among four, while others liked the introduction because it made them feel like they were "not alone" in having had abortions.

It's more like, it's okay. It's not like you are the only person on this earth that's ever had an abortion, and it's showing there bas been research on it. (Reported an abortion)

Some felt that this introduction inappropriately suggested that abortion was "cool" or trendy.

Because I wouldn't want to be in that statistic. I wouldn't want to be the one of four. (Reported an abortion)

The 'Legal' introduction was the least preferred introduction of those examined, as many respondents felt the introduction was unhelpful, impersonal, or encouraged abortion (Table 3, Option 5). Many felt that the introduction politicized the question, and several respondents questioned whether abortion was legal everywhere in the US.

It becomes a political thing, in this sense, to me at least. It feels more like a political question than it does a medical question about reproductive bealth. (Reported an abortion)

However, some felt the introduction may be helpful to alert respondents, particularly in states that are hostile to abortion, that they would not be in "trouble" for reporting an abortion.

It feels more comfortable because I am not going to be afraid of answering yes or no, because I am not doing sometbing illegal. (Reported an abortion)

\section{Influence of abortion stigma on reporting}

As participants shared their feelings and thoughts during the cognitive interview about the different abortion items, stigma frequently came up as a potential influence on reporting. Many respondents that reported an abortion named feelings of shame, guilt, fear of judgment, and generally not being "proud" of their decision when disclosing their experience. Experiences of stigma made them hesitant to discuss having had an abortion.

If it's a setting where I know people or I feel people are going to judge me, then maybe I'll just skip it [mentioning the abortion]. (Reported an abortion) 
I think I am reluctant sometimes to tell interviewers about pregnancies that ended in abortion, because I don't know their thoughts and I don't know if they'll judge me. (Reported an abortion)

Similarly, question language that evoked detailed memories of abortion experiences were not viewed positively by respondents that reported an abortion, since it made them relive experiences that they may not want to dwell on.

I think it's actually their experience, like, was it painful? Did you have somebody with you when you went? Why did you have to get an abortion? So, it's bringing back up those emotions and the memory of that. (Reported an abortion)

Some respondents preferred the phrase "termination" to "abortion", as they felt like the word itself was too jarring. Some respondents were uncomfortable using the word "abortion" at all.

It should be "termination" or "terminate". "Have you ever had a termination?" Rather than "abortion" - it's the word itself that could be a little too, um, just in your face, you know. (Reported an abortion)

There is such a stigma about [abortion] in our society, and that's why I never used the word before because I felt like termination sounded a little better, because it wasn't like we screwed up and I got pregnant accidentally. (Reported an abortion)

\section{Discussion}

Despite the well documented phenomenon of abortion underreporting, few advances have been made in understanding how to improve self-reports of abortion in surveys. This is one of the first studies to qualitatively and systematically investigate women's comprehension of and reaction to a number of changes in the way abortion questions are posed in surveys. Our use of cognitive interviews is a valuable step in developing and implementing question items to improve the survey measurement of abortion. The results of the qualitative analysis identified several promising approaches to measuring abortion in surveys while also finding evidence that certain approaches are unlikely to yield meaningful improvements in abortion reporting.

Many participants responded positively to the question design that included abortion as part of a list of other less stigmatized sexual and reproductive health services that women receive, such as a pregnancy test or a Pap smear. Placing abortion in the context of more socially acceptable health services appears to reduce social desirability bias around reporting of abortion. This is a notable shift from the conventional context of abortion in surveys, which situates abortion experiences alongside other pregnancies (such as in the NSFG interviewer-administered question series).(26) We encourage further research exploring how best to refine the services provided on this list. Interestingly, the NSFG does have a section on health care services which includes 
abortion in a different battery of sexual and reproductive health services received in the past 12 months, but the short timeframe and low reporting has constrained its analytic use; for example, only 32 participants reported an abortion in the 12 months preceding the 2017-2019 NSFG.(26)

A second approach that appeared successful in the cognitive interviews was to solicit reports of whether respondents had an abortion rather than the number of abortions they had. Our findings also suggest that asking a yes/n" item about any abortion reduces stigma associated with reporting multiple abortions, a finding that is supported by other research that found that reporting multiple abortions appears to be more sensitive than reporting one abortion.(27) Respondents suggested that they would prefer only to be asked to report the number of abortions if this information is needed for a specific purpose. The single question item about any abortion, which does not probe on number, may meet researchers' needs, depending on the research question they are asking. Researchers should be cautious in trying to collect more detailed information if it reduces data quality or completeness.

Additionally, most respondents expressed support for the use of an introduction prior to a question about their abortion history. However, there may not be a single introduction that improves reporting among all respondents, as we found inconsistent reactions to the introductions that we designed. Some respondents may find an introduction motivating or destigmatizing, while others may be less prone to report if they have a negative response to the introductory text. However, it is important to grapple with the findings that the 'Reluctant' introduction modified from the NSFG typically garnered negative feedback, and future work should further examine developing and utilizing improved introductions before asking about abortion.

Several approaches we investigated in these interviews did not seem likely to be successful at improving reporting. We found that explicitly including medication and surgical abortion in question wording did not improve comprehension. Instead, respondents reacted negatively to this question wording and felt that the detail was unnecessarily intrusive. Responses to this question indicated that respondents had comprehension issues regarding what experiences to report as abortion that our questions did not fully address. We plan to explore this further in subsequent analyses. Although trying to identify the type of abortion may be appropriate for some data collection efforts, again, researchers should be cautious in collecting more detailed information if it reduces the quality of reporting. Additionally, our efforts to first ask about confidantes' abortion experiences did not seem to prime women to report their own abortions. Furthermore, our participants responded negatively to the contextualization of abortion among fertility and childbearing. Their feedback is supported by the literature, which suggests that associating abortion with other pregnancies increases concerns of stigma.(3)

Further efforts to improve survey items for measuring abortion should be responsive to two additional factors not fully examined in this study. First, the sensitivity of abortion-and the willingness to report an 
abortion - is differentially experienced by women depending on their personal and community characteristics (28) and there may not be a one size fits all approach to question wording that improves reporting for all women. In this study, participants were highly educated and most had incomes of at least $200 \%$ above the federal poverty level. Given sample size constraints, we were not able to examine responses across demographic subgroups,(12) so more investigation of variability is needed.

Similarly, while this study was designed to explore reporting across different state contexts, we did not find major differences between respondents in Wisconsin and New Jersey. Responses may have been different in states with even greater abortion stigma or politicization of abortion access, and other contexts should be considered.(25)

One limitation of the study was the inclusion of an abortion question during the eligibility screening process which may have lost some possible respondents who are uncomfortable with the topic. It may mean that our respondents are different from other people who have had abortions in their level of willingness to disclose. By including people who did not report an abortion when asked in the screener (but may not have been truthful), we hoped to mitigate this effect and include respondents who had abortions but would typically choose not to report their experience. In the interview, the responses of participants who did and did not report a prior abortion were generally similar. One notable difference is that those who did not report a prior abortion often described abortion as highly stigmatized, but this perception of stigma may not directly influence reporting if they have not had an abortion. Reporting can only be improved among women who have had an abortion and thus these respondents should be the focus of new design efforts. However, efforts to target respondents who have had an abortion are complicated by the paradoxical challenge of needing to concentrate efforts on those respondents who are most hesitant to report the sensitive behavior under study.

Our findings are also limited in that they cannot speak to question order since we randomized the order in which questions and introductions were presented to respondents. We recognize that this study used a modified approach cognitive interview technique, given that we were not testing an entire questionnaire but rather attempting to improve questions on abortion history. While this study's use of cognitive interviews offers an innovative approach to improving measurement of abortion through careful development of new survey items, further research is needed to determine if findings from this qualitative work can lead to improvements in reporting in the context of a complete survey. We will be testing this explicitly in an experimental study that will adapt the most promising approaches identified here and test them against one another to ascertain which are most effective in improving abortion reporting. 


\section{Conclusions}

Abortion is extensively underreported on surveys, which undermines the provision of health care services and the quality of research on pregnancy experiences. Our findings highlight the influence of question wording on motivating the accurate reporting of abortions. We found that respondents most preferred answering a single yes/no question about whether they had ever had any abortions. In addition, they preferred to be asked about abortion in the context of other sexual and reproductive health services, rather than other pregnancy outcomes. Finally, our respondents indicated that introductions to abortion questions could play a role in motivating respondents to answer accurately. Improving abortion reporting in surveys will improve the quality of research on the role of pregnancy in people's lives.

\section{List of Abbreviations}

United States (US)

National Survey of Family Growth (NSFG)

Face-to-face (FTF)

Sexual and reproductive health $(\mathrm{SRH})$

Federal poverty level (FPL)

Emergency contraceptive (EC)

Audio computer-assisted self-interviewing (ACASI)

Tests of General Educational Development (GED) 


\section{Declarations}

Ethics of approval and consent to participate: The Guttmacher Institute's federally registered Institutional Review Board (DHHS identifier IRB00002197) reviewed and approved the study.

Consent for publication: Not applicable.

Availability of data and methods: Study participants were asked a separate, optional consent to allow their data to be made publicly available. De-identified data from the study will be hosted by the Qualitative Data Repository at Syracuse University; researchers can apply for access [LINK FORTHCOMING].

Competing interest: The authors declare that they have no competing interests.

Funding: Research reported in this publication was supported by the Eunice Kennedy Shriver National Institute of Child Health and Human Development of the National Institutes of Health under Award Number R01HD084473. The content is solely the responsibility of the authors and does not necessarily represent the official views of the National Institutes of Health.

Authors' contributions: JM designed the interview guide, conducted interviews, analyzed and interpreted the data, and was the lead contributor to writing the manuscript. MK contributed to the design of the interview guide, analyzed and interpreted the data, and was a major contributor to writing the manuscript. AV designed the interview guide, conducted interviews, analyzed and interpreted the data, and contributed substantively to the writing the manuscript. LDL was the lead contributor to the conception of the work, and contributed substantively to the writing of the manuscript. All authors read and approved the final manuscript.

Acknowledgments: The authors gratefully acknowledge the critical feedback and contributions from the following colleagues: Lori Frohwirth, Margaret Giorgio, Megan Kavanaugh, Kathryn Kost, Ashley Little, Kimberley Lufkin, Isaac Maddow-Zimet, Ann Moore, and Elizabeth Nash. 


\section{References}

1. Jones R, Jerman J. Population Group Abortion Rates and Lifetime Incidence of Abortion: United States, 2008-2014. Am J Public Health. 2017 Oct 19;107(12):1904-9.

2. Jones R, Witwer E, Jerman J. Abortion Incidence and Service Availability in the United States, 2017 [Internet]. Guttmacher Institute; 2019 Sep [cited 2021 Apr 16]. Available from: https://www.guttmacher.org/report/abortion-incidence-service-availability-us-2017

3. Kumar A, Hessini L, Mitchell EMH. Conceptualising abortion stigma. Cult Health Sex. 2009 Aug 1;11(6):625-39.

4. Norris A, Bessett D, Steinberg JR, Kavanaugh ML, De Zordo S, Becker D. Abortion stigma: a reconceptualization of constituents, causes, and consequences. Womens Health Issues Off Publ Jacobs Inst Womens Health. 2011 Jun;21(3 Suppl):S49-54.

5. Cutler AS, Lundsberg LS, White MA, Stanwood NL, Gariepy AM. Characterizing community-level abortion stigma in the United States. Contraception. 2021 Mar 28;

6. Scott R. Understanding differences in conception and abortion rates among under 20s in Britain and France: Examining the role of disadvantage [Internet] [doctoral]. London School of Hygiene \& Tropical Medicine; 2017 [cited 2018 Jan 2]. Available from: http://researchonline.lshtm.ac.uk/3482688/

7. Yan T. Consequences of Asking Sensitive Questions in Surveys. Annu Rev Stat Its Appl. 2021;8(1):109_ 27.

8. Lindberg L, Kost K, Maddow-Zimet I, Desai S, Zolna M. Abortion Reporting in the United States: An Assessment of Three National Fertility Surveys. Demography. 2020 Jun 1;57(3):899-925.

9. Desai S, Lindberg L, Maddow-Zimet I, Kost K. The Impact of Missing Abortions on Pregnancy-Related Research, Maternal and Child Health. forthcoming.

10. Jones RK, Philbin J, Kirstein M, Nash E. New Evidence: Texas Residents Have Obtained Abortions in at Least 12 States That Do Not Border Texas [Internet]. New York, NY: Guttmacher Institute; 2021 Nov [cited 2021 Dec 17]. (Policy Analysis). Available from: https://www.guttmacher.org/article/2021/11/new-evidence-texas-residents-have-obtained-abortionsleast-12-states-do-not-border 
11. Moreau C, Bajos N, Bouyer J, Group TC. Question Comprehension and Recall: The Reporting of Induced Abortions in Quantitative Surveys on the General Population. Popul Engl Ed 2002-. 2004;59(3/4):439-54.

12. Lindberg L, Scott R. Effect of ACASI on Reporting of Abortion and Other Pregnancy Outcomes in the US National Survey of Family Growth. Stud Fam Plann. 2018;49(3):259-78.

13. Sully E, Giorgio M, Anjur-Dietrich S. Estimating abortion incidence using the network scale-up method. Demogr Res. 2020 Dec 16;43(56):1651-84.

14. Sedgh G, Keogh SC. Novel approaches to estimating abortion incidence. Reprod Health. 2019 Apr 18;16(1):44.

15. Bell SO, Bishai D. Can a List Experiment Improve Validity of Abortion Measurement? Stud Fam Plann. 2019;50(1):43-61.

16. Kissling A, Jackson HM. Estimating Prevalence of Abortion Using List Experiments: Findings from a Survey of Women in Delaware and Maryland. Womens Health Issues. 2022 Jan 1;32(1):33-40.

17. Moseson H, Filippa S, Baum SE, Gerdts C, Grossman D. Reducing underreporting of stigmatized pregnancy outcomes: results from a mixed-methods study of self-managed abortion in Texas using the list-experiment method. BMC Womens Health. 2019 Dec;19(1):113.

18. Cowan SK, Wu LL, Makela S, England P. Alternative Estimates of Lifetime Prevalence Of Abortion from Indirect Survey Questioning Methods. Perspect Sex Reprod Health. 2016 Dec 1;48(4):229-34.

19. Groves RM, Fowler FJ, Couper MP, Lepkowski JM, Singer E, Tourangeau R. Chapter 7: Questions and Answers in Surveys. In: Survey Methodology. Second. Hoboken, NJ: Wiley \& Sons; 2009. p. 217-57.

20. Tourangeau R, Yan T. Sensitive Questions in Surveys. Psychol Bull. 2007 Sep;133(5):859-83.

21. The psychology of survey response. New York, NY, US: Cambridge University Press; 2000. xiii, 401 p. (Tourangeau R, Rips LJ, Rasinski K, editors. The psychology of survey response).

22. Willis GB, Artino AR. What Do Our Respondents Think We're Asking? Using Cognitive Interviewing to Improve Medical Education Surveys. J Grad Med Educ. 2013 Sep;5(3):353-6.

23. Hickman S, Finocharo J, Whitfield B, Griffith I, Manlove J. Measuring Unprotected Sex Among Black and Latinx Women Ages 18 to 20, Based on Cognitive Interviews [Internet]. Child Trends; 2021 Mar 
[cited 2021 Jun 29]. Available from: https://www.childtrends.org/publications/measuring-unprotectedsex-among-black-latinx-women-ages-18-20-based-on-cognitive-interviews

24. Willis GB. Cognitive interviewing: a "how to" guide. Baltimore, Maryland: Research Triangle Institute; 1999.

25. Nash E. State Abortion Policy Landscape: From Hostile to Supportive [Internet]. Guttmacher Institute. 2019. Available from: https://www.guttmacher.org/article/2019/08/state-abortion-policy-landscapehostile-supportive\#

26. 2017-2019 NSFG Female Respondent Section F Codebook. In: NSFG Codebook [nternet]. National Survey of Family Growth; 2021 [cited 2021 Jun 29]. Available from: https://www.cdc.gov/nchs/data/nsfg/2017-2019_NSFG_FemResp_SectionF_Codebook-508.pdf

27. Kopplin G, Desai S, Lindberg L. Women's reports of multiple abortions: implications for survey data quality. Contraception. 2017 Oct;96(4):273.

28. Maddow-Zimet I, Lindberg LD, Castle K. State-Level Variation in Abortion Stigma and Women and Men's Abortion Underreporting in the USA. Popul Res Policy Rev [Internet]. 2021 May 20 [cited 2021 Jun 29]; Available from: https://doi.org/10.1007/s11113-021-09657-4 
Appendix Table 1. Modified question and introduction wordings used in the cognitive interviews

\begin{tabular}{|c|c|c|}
\hline \multicolumn{2}{|r|}{ Approach } & Question Wordings \\
\hline 1 & $\begin{array}{l}\text { Pregnancy context (modified } \\
\text { NSFG ACASI) }\end{array}$ & $\begin{array}{l}\text { Sometimes women are reluctant to tell an interviewer } \\
\text { about some of their pregnancies, especially those } \\
\text { pregnancies that ended in abortion or with babies they no } \\
\text { longer live with. In the next set of questions, please give a } \\
\text { complete count of all your pregnancies. } \\
\text { In your lifetime, how many pregnancies have you had } \\
\text { that resulted in a live birth, that is, in a baby born alive? } \\
\text { [Yes/No] } \\
\text { In your lifetime, how many pregnancies have you had } \\
\text { that ended in abortion? [Yes/No] } \\
\text { In your lifetime, how many pregnancies have you had } \\
\text { that ended in miscarriage, stillbirth, or ectopic pregnancy? } \\
\text { [Yes/No] }\end{array}$ \\
\hline 2 & $\begin{array}{l}\text { Pregnancy context (modified } \\
\text { NSFG FTF) }\end{array}$ & $\begin{array}{l}\text { How many times have you been pregnant in your life? [\#] } \\
\text { In which of the ways shown on this card did the } \\
\text { pregnancy end? [Select one] } \\
\text { - Miscarriage } \\
\text { - Stillbirth } \\
\text { - Abortion } \\
\text { - Ectopic or tubal pregnancy } \\
\text { - Live birth by cesarean section } \\
\text { - Live birth by vaginal delivery }\end{array}$ \\
\hline 3 & Priming using confidantes & $\begin{array}{l}\text { As far as you know, how many of your friends or family } \\
\text { have had an abortion? [\#] }\end{array}$ \\
\hline 4 & $\begin{array}{l}\text { Sexual and reproductive health } \\
\text { services context (modified NSFG } \\
\text { FTF) }\end{array}$ & $\begin{array}{l}\text { In your lifetime, have you received any of the following } \\
\text { medical services from a doctor or other medical care } \\
\text { provider? } \\
\text { - A pregnancy test? [Yes/No] } \\
\text { - An abortion? [Yes/No] } \\
\text { - A method of birth control or a prescription for a } \\
\text { method? [Yes/No] } \\
\text { - Emergency contraception, also known as "Plan B" or } \\
\text { the "Morning-after pill," or a prescription for it? } \\
\text { [Yes/No] } \\
\text { - Prenatal care? [Yes/No] } \\
\text { - A breast exam? [Yes/No] } \\
\text { - A test for a sexually transmitted disease? [Yes/No] }\end{array}$ \\
\hline
\end{tabular}




\begin{tabular}{|c|c|c|}
\hline 5 & Specifying abortion methods & $\begin{array}{l}\text { There are different methods of abortion. Some are } \\
\text { described as surgical abortions, and some are described as } \\
\text { medication abortions. Thinking about these methods, } \\
\text { have you ever had an abortion? [Yes/No] }\end{array}$ \\
\hline 6 & $\begin{array}{l}\text { Separating any and number of } \\
\text { abortions }\end{array}$ & $\begin{array}{l}\text { Have you ever had an abortion? [Yes/No] } \\
\text { In your lifetime, how many abortions have you had? [\#] }\end{array}$ \\
\hline \multicolumn{2}{|r|}{ Option } & Introduction Wordings \\
\hline 1 & $\begin{array}{l}\text { Reluctance (modified NSFG } \\
\text { ACASI) }\end{array}$ & $\begin{array}{l}\text { Sometimes women are reluctant to tell an interviewer } \\
\text { about some of their pregnancies, especially those } \\
\text { pregnancies that ended in abortion. }\end{array}$ \\
\hline 2 & Helping & $\begin{array}{l}\text { Answering the following question helps to improve } \\
\text { family planning and health services. }\end{array}$ \\
\hline 3 & Common & There are a lot of reasons why people get abortions. \\
\hline \multirow[t]{2}{*}{4} & \multirow[t]{2}{*}{ Statistic } & $\begin{array}{l}1 \text { in } 4 \text { American women will have an abortion in their } \\
\text { lifetime. }\end{array}$ \\
\hline & & $\begin{array}{l}\text { Research shows that } 1 \text { in } 4 \text { American women will have an } \\
\text { abortion in their lifetime. }\end{array}$ \\
\hline 5 & Legal & Abortion is a medical procedure. \\
\hline
\end{tabular}

Note: Response options given in brackets. 